\title{
Knowledge and Attitude of Primary School Teachers on Attention Deficit Hyperactivity Disorder
}

\author{
E.M.Fahmy, S.T.El-Bakry, A.M.Hegab and S.M.Kasem \\ Neuropsychiatry Dept., Faculty of Medicine, Benha Univ., Benha, Egypt \\ E-Mail: A.ahmed56@gmail.com
}

\begin{abstract}
Background: Attention Deficit Hyperactivity disorder (ADHD) is one of the most common neuropsychiatric childhood behavioral disorders, affecting children. Teachers are often the first persons responsible for identifying children with attention deficit hyperactivity disorder (ADHD) and are increasingly being called on to help manage such children. International studies have revealed variable levels of knowledge and attitude among teachers regarding attention-deficit hyperactivity disorder (ADHD). We sought to assess teachers' knowledge of and attitudes toward ADHD in Menya ElQamh city, Sharkia governorate, Egypt. This study investigated Egyptian primary school teachers' ADHD knowledge and their attitudes towards children with this condition. A standardized self-report questionnaire was completed by a convenience sample of 253 teachers recruited from 6 primary schools in Menya El-Qamh city, Sharkia governorate, Egypt. Aim of the study: Determine knowledge and attitude of primary school teachers regarding attention deficit hyper activity disorder (ADHD) and casting light on the correlation between demographic data of primary school teachers and their knowledge and attitude towards ADHD.Methods and Results: A standardized self-report questionnaire was completed by a convenience sample of 253 teachers recruited from 6 primary schools in Menya El-Qamh city, Egypt. Findings revealed a gap in teachers' knowledge that extended across all aspects of ADHD causes, symptoms and different aspects of management. Teachers' attitude towards children with ADHD was also lower than expected, where many misconceptions about the causes and management of ADHD have emerged. The almost absent formal and informal support of children with ADHD have contributed to these results. The findings stress the need for implementing special programs targeting school teachers and reforming pre-service teachers' lecture to meet the needs of children with ADHD.
\end{abstract}

Keywords: Attention-deficit hyperactivity disorder, Knowledge, Attitude; primary School Teachers, Primary Schools.

\section{Introduction}

Attention-deficit hyperactivity confusion (ADHD) may be An psychiatric jumble that need been assessed on influence $3-7 \%$ from claiming school-aged know youngsters (American Psychiatric Association, 2013). Similarly as of 2005, a Audit evaluated those overall pooled predominance for adhd on a chance to be $5.3 \%$ [40].

Those jumble may be a greater amount normal to young men over girls, for A percentage reports estimating the proportion should make six young men should person young lady (Sharma, 2020). An investigation led clinched alongside 2009 need demonstrated An secondary pervasiveness of adhd "around school-aged children, arriving at over $6.2 \%$ for a male should female proportion about 2. 4:1 [3]. This variety will be identified with contrasts in the symptomatic criteria Also definitions as opposed to contrasts to clinical presentation [23], conduct [13], and right on social insurance Also dialect [2].

Adhd may be described Eventually Tom's perusing developmentally unseemly levels about inattention, impulsivity and hyperactivity that impact children's behavioral Furthermore academic execution in the classroom [7]. Due to its symptoms, adhd reasons functional, social, instructive and gang impairments [49, 22].

An significant trouble will be put ahead kids for ADHD, their groups Furthermore class teachers, Concerning illustration there are no uncommon benefits will administer to their general Also particular issues. Unfortunately, there may be no formal majority of the data or arrangement should aide the finding alternately medicine for such states for schools. Same time a amount for exploration ventures focusing on know youngsters with adhd have been directed clinched alongside Egypt, little from claiming these undertakings bring centered ahead one school instructors. Beginning school to those 1 st time could be a testing knowledge for exactly Youngsters. Know youngsters for adhd might background further challenges as an aftereffect of their condition [46].

It need been accounted that learners with adhd experience issues administering consideration to in length periods about time What's more manage persistency worth of effort effort, including staying centered in the classroom, finishing assignments, staying once their seats, or doing classroom exercises. Therefore, it is critical will recognizing know youngsters for adhd What's more actualize all the extraordinary instructive methodologies will assistance them succeed these academic and mental challenges [28]. Kids for adhd need aid altogether less averse to have temperament issue (Major Depression: 3 times; Dysthymia: 7 times; bipolar Disorder: 7 times), tension issue (Generalized tension Disorders, PTSD Furthermore frenzy Disorder: 3 times) Also substance utilization issue (alcohol dependence: 3 times and drug dependence: 8 times) higher over typical kids [35].

Even-though not constantly on behavioral side effects need aid mitigated by medications, thereabouts conduct technique modification, What's more instructive intercessions need aid paramount in the procedure about treating indications of adhd [47]. Those effects of a 
substantial randomized regulated trial suggester that prescription alone may be better than behavioral help alone, Anyway that the blending of behavioral help Furthermore solution need extra profit over solution alone [17]. There are a significant number alternatives accessible should treat kin diagnosed with adhd. Those choice with the best exploratory help will be an assortment from claiming medications [16].

An key component in the analysis What's more management about class know youngsters for adhd may be school instructors. Likewise educators nearly associate for their scholars once An Every day basis, they have the ability to provide critical data regarding adhd history and symptoms, Also help children's medicine arrangements. An investigation directed for Washington, dc found that instructors and different class work force were frequently all the those To begin with should recommended the finding for adhd to kids [44]. A standout amongst those tests for treating adhd is teachers' address should perceive those indications of the condition that have impacted their capability will encourage the vital medicine required will streamline school-related results. For educators on remember Youngsters with possibility adhd Furthermore give fitting care, it is critical that they need An heartless information for this jumble and An certain disposition towards kids with this condition [11].

Attitudes concerning those acknowledgement about adhd Likewise a substantial medicinal condition need an effect on the recognized compelling reason for benefits [19]. Teachers' learning and mentality something like adhd In impact those execution of people with adhd to classroom hones Furthermore exercises [29].

Social insurance experts camwood help educators with create methodologies will assistance Push those classroom execution from claiming understudies with adhd. The association between educators Also social insurance suppliers will be urgent. As social insurance suppliers rely on upon teachers' enter on assess Also wrist bindings Youngsters for ADHD, they give these educators with a great wellspring for majority of the data [32].

Therefore, should comprehend how educators deal with kids for ADHD, it may be imperative will evaluate those teachers' level from claiming adhd information Also inspect their attitudes towards Youngsters with this condition. The reason for this examine might have been with inspect the learning and attitudes of essential school instructors around adhd Previously, Menya El-Qamh city, egypt Furthermore describe those association between their information What's more state of mind towards Youngsters for adhd.

\section{Technique}

\subsection{Participants}

A cross-sectional spellbinding correlational configuration might have been utilized on analyze the information Furthermore disposition of elementary class educators towards scholars with adhd. A accommodation example starting with 6 of the The greater part approachable public, private Also extraordinary needs essential schools to Menya El-Qamh city, egypt might have been welcome to take an interest in the ponder. Class educators were welcome to partake in the investigation. 253 educators attempting in the 6 schools took an interest in the study. At members were chose according focus number. The study might have been carried through those Academic quite a while 20182019. Secrecy might have been guaranteed will know members Furthermore information utilized to this examine were stripped for personally recognizable proof majority of the data.

\subsection{Instrument}

An self-report questionnaire utilized within past reports (51) might have been adjusted to utilization in this study In view of those authors' survey Also reaction from An pilot contemplate. The last instrument flying held three areas. The primary (Section An) gathered demographic data around each respondent including age, sex, educating experience, instructor's testament lecture, amount of kids over person class Furthermore Normal suspected number for know youngsters for adhd in every population. Area $b$ might have been proposed on accomplish teachers' real learning for adhd and held 42 inquiries with correct, incorrect, Furthermore not beyond any doubt alternatives. A few inquiries were worded in the negative will forestall irregular fruition Eventually Tom's perusing members. You quit offering on that one purpose might have been honored to each right response and the comes about for every inquiry summed should yield an aggregate learning score. The most extreme workable score might have been thusly 42 . For this analysis, both off replies Furthermore don't recognize were acknowledged inaccurate in spite of the fact that those rundown judgment for each reaction is Additionally introduced. Segment c's evaluated teachers' attitudes to adhd by the utilization for 33 proclamations with correct, incorrect, Also not indeed choices. A few things were once more opposite scored to guarantee aware fruition of the questionnaires. For every question, those intend Furthermore standard deviation were computed.

\subsection{Methods}

Schools were selected by stratified random sampling and overall, teachers from 6 schools took part in the study. Two hundred and fifty-three (253) questionnaires were completed twice one as a pre-test and the other as a post-test. The questionnaire was completed on several days due to the lack of all school teachers at the same time because of their class schedule and supervision or the absence of some teachers in the meeting room or the school's theater according to the number of participants of each school and the availability of the space. Each questionnaire containned three sections of questions of demographic data, questions of knowledge and of attitude. This representative teacher received a number of packages and distributed them to his or her colleagues who were asked to complete them on a voluntary basis. 
For the sake of anonymity, teachers were asked to separate consent forms from questionnaires. Both were then returned to the researcher in separate envelopes.

\subsection{Statistical analysis}

The collected data was revised, coded, tabulated and introduced to a PC using Statistical package for Social Science (IBM Corp. Released 2017. IBM SPSS Statistics for Windows, Version 25.0. Armonk, NY: IBM Corp). Data were presented and suitable analysis was done according to the type of data obtained for each parameter. Kolmogorov-Smirnov test was done to test the normality of data distribution. Significant data was considered to be nonparametric. Categorical data were presented as frequency and percentages while quantitative data were expressed as mean \pm standard deviation and range. In the statistical comparison between the different groups, Student $\mathrm{T}$ Test was used to assess the statistical significance of the difference between two study group means, for the comparison of more than two groups' means, one way analysis of variance (ANOVA) was used, the relationship between two qualitative variables was examined using Chi-Square test, the relationship between two qualitative variables when the expected count is less than 5 in more than $20 \%$ of cells was examined using Fisher's exact test, the strength of association between two quantitative variables was assessed by correlational analysis. Reliability test was made by using Cronbach's Alpha and was (alpha $=0.841$ ) which is very good. $\mathrm{P}$ value is significant if $<0.05$ at confidence interval $95 \%$.

\section{Results}

Of the 300 questionnaires distributed, 265 were returned. Twelve questionnaires were discarded because participants did not complete either the pre-test or the post-test giving a final sample size of 253 and a response rate of $84.3 \%$.

\subsection{Demographic information}

Given that this was the first time this instrument was used in our population, we sought to test its reliability; this yielded a Cronbach's alpha score of 0.841 suggesting very good internal consistency in our population. The final sample consisted of 253 primary school teachers from 6 primary schools drawn from Menya El-Qamh city, Sharkia governorate, Egypt. The age of teachers ranged from 24 to 60 years, $43.9 \%(n=$ 111) were above 45 years, $19.8 \%(n=50)$ below 30 years and $36.4 \%(n=92)$ were from 30 up to 45 years. Of those sampled, $85 \%(\mathrm{n}=215)$ were female and $15 \%(\mathrm{n}=38)$ were male teachers. Years of teaching experience were assessed as below 5 years $18.6 \%(n=47)$, from 5 up to 10 years $22.9 \%(n=58)$ and above 10 years $58.5 \%(n=148)$. With respect to predicting taught a child with ADHD, $2 \%(\mathrm{n}=5)$ of teachers responded that they had not taught a child with ADHD, while 52.2\% $(\mathrm{n}=132)$ responded that they had taught 1 to 4 children with ADHD in each class and $45.8 \%(\mathrm{n}=116)$ had taught more than 4 children with ADHD in each class. $43.1 \%(n=109)$ were specialized in literary subjects, $34 \%(\mathrm{n}=86)$ in scientific ones and $22.9 \%(n=58)$ in activities. $66.8 \%(n=169)$ of teachers were from governmental schools, $24.5 \%(n=62)$ from private ones and $8.7 \%(\mathrm{n}=22)$ from special needs. $68 \%(n=172)$ of teachers are married and $74.7 \%(n=189)$ were highly graduated Tables (1-6).

Table (1) Socio-demographic characteristics of the participating teachers.

\begin{tabular}{|c|c|c|c|}
\hline & & \multicolumn{2}{|c|}{$\begin{array}{c}\text { Total } \\
\mathbf{N}=253\end{array}$} \\
\hline & & $\mathbf{N}$ & $\%$ \\
\hline \multirow[t]{2}{*}{ Sex } & Male & 38 & $15.0 \%$ \\
\hline & Female & 215 & $85.0 \%$ \\
\hline \multirow[t]{3}{*}{ Age (years) } & $<30$ & 50 & $19.8 \%$ \\
\hline & $30-45$ & 92 & $36.4 \%$ \\
\hline & $>45$ & 111 & $43.9 \%$ \\
\hline \multirow[t]{3}{*}{ Marital status } & Single & 46 & $18.2 \%$ \\
\hline & Married & 172 & $68.0 \%$ \\
\hline & Other & 35 & $13.8 \%$ \\
\hline \multirow[t]{3}{*}{ Educational level } & Intermediate & 16 & $6.3 \%$ \\
\hline & Higher & 189 & $74.7 \%$ \\
\hline & Postgraduate & 48 & $19.0 \%$ \\
\hline \multirow[t]{3}{*}{ Type of school } & Governmental & 178 & $70.4 \%$ \\
\hline & Private & 58 & $22.9 \%$ \\
\hline & Special abilities & 17 & $6.7 \%$ \\
\hline \multirow[t]{3}{*}{ Years of experience } & $<5$ & 47 & $18.6 \%$ \\
\hline & $5-10$ & 58 & $22.9 \%$ \\
\hline & $>10$ & 148 & $58.5 \%$ \\
\hline \multirow[t]{3}{*}{ Specialty } & Literary & 109 & $43.1 \%$ \\
\hline & Scientific & 86 & $34.0 \%$ \\
\hline & Activities & 58 & $22.9 \%$ \\
\hline \multirow[t]{3}{*}{ Number of students in the class } & $<30$ & 14 & $5.5 \%$ \\
\hline & $30-50$ & 118 & $46.6 \%$ \\
\hline & $>50$ & 121 & $47.8 \%$ \\
\hline \multirow[t]{3}{*}{ Number of students with ADHD in the class } & 0 & 5 & $2.0 \%$ \\
\hline & $1-4$ & 132 & $52.2 \%$ \\
\hline & $>4$ & 116 & $45.8 \%$ \\
\hline
\end{tabular}




\section{Teachers' knowledge about ADHD}

Forty-two questions were used to assess knowledge. Overall, the mean total knowledge score was 18.7, 24.8 $(\mathrm{SD}=5.6,2.9)$ of pre-test and post-test respectively. This corresponds to $91.7 \%$ of the overall pre-test knowledge was low and $75.1 \%$ of the overall post-test knowledge was low.

The overall knowledge and attitude levels were classified into three categories following Bloom's cut-off point criteria. In the present study, knowledge categories became better after lecture $(\mathrm{p}<0.001)$.

Table (2) Comparison of overall knowledge of teachers before and after lecture.

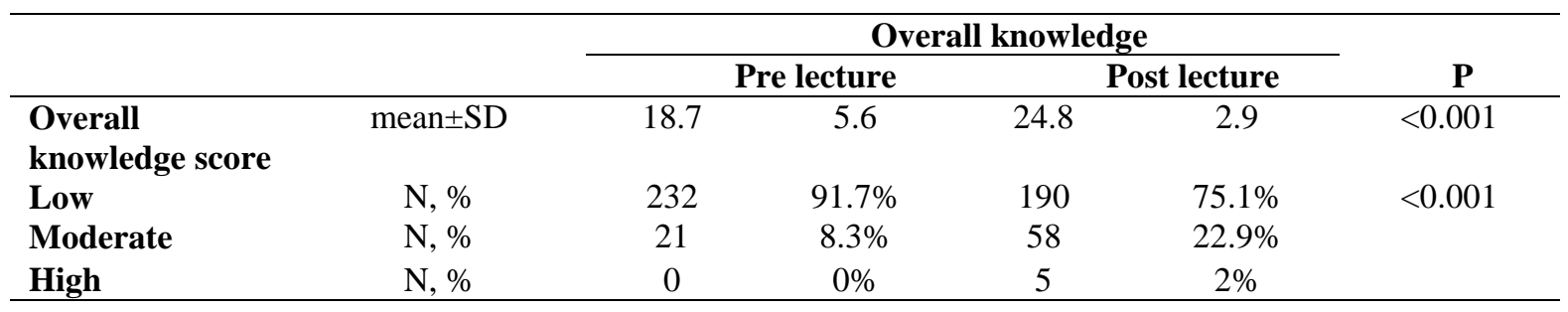

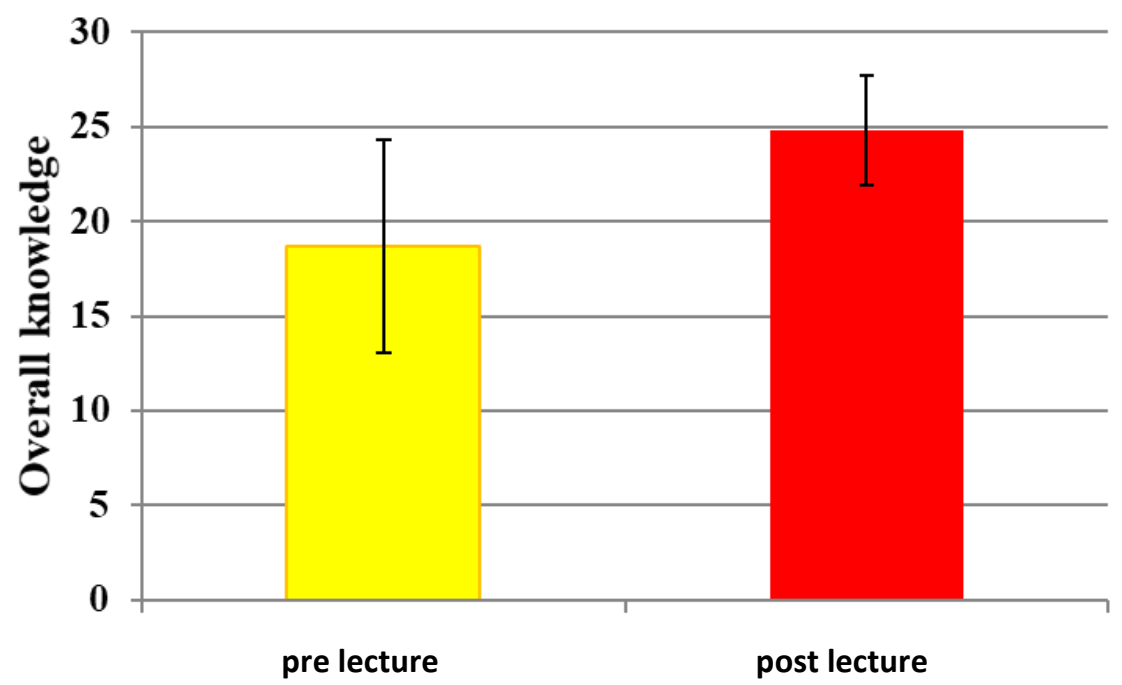

Fig (1) Overall knowledge score of the teachers before and after the lecture.

\section{Overall knowledge}

pre lecture $\quad$. post lecture

$91.7 \%$

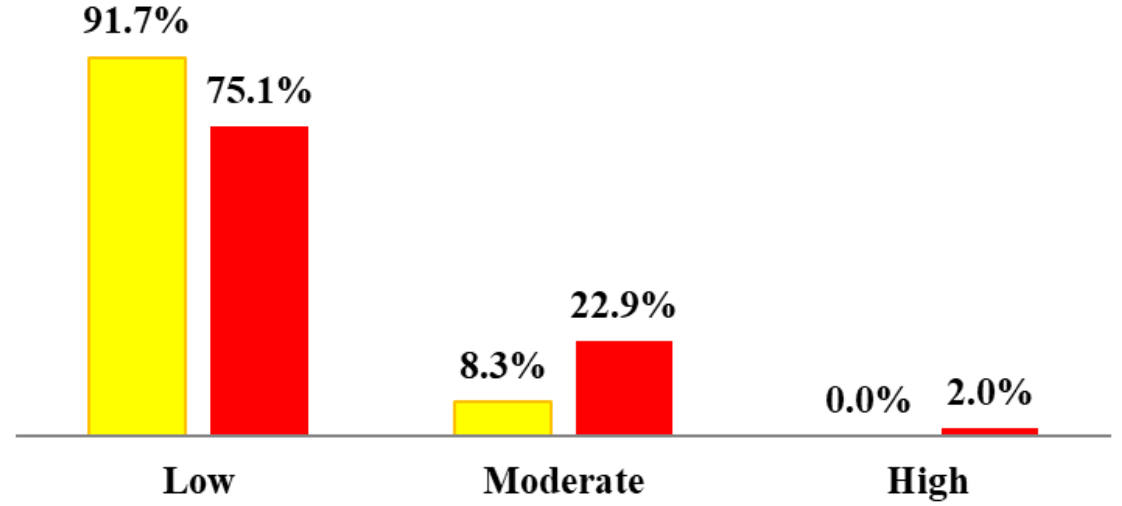

Fig (2) Overall knowledge categories before and after the lecture. 
Thirty-three questions were used to assess attitude. Overall, the mean total attitude score was $14.9,18.1(\mathrm{SD}=5,2.1)$ of pre-test and post-test respectively. This corresponds to $88.1 \%$ of the overall pre-test attitude was low and $73.1 \%$ of the overall post-test attitude was low.

The overall attitude levels were classified into three categories following Bloom's cut-off point criteria. In the present study, attitude categories became better after lecture $(\mathrm{p}<0.001)$.

Table (3) Comparison of overall attitude before and after lecture of the teachers.

\begin{tabular}{|c|c|c|c|c|c|c|}
\hline & & \multicolumn{5}{|c|}{ Overall attitude } \\
\hline & & \multicolumn{2}{|c|}{ Pre lecture } & \multicolumn{2}{|r|}{ Post lecture } & \multirow{2}{*}{$\frac{\mathbf{p}}{<0.001}$} \\
\hline overall attitude & mean \pm SD & 14.9 & 5 & 18.1 & 2.1 & \\
\hline Low & $\mathrm{N}, \%$ & 223 & $88.1 \%$ & 185 & $73.1 \%$ & $<0.001$ \\
\hline Moderate & $\mathrm{N}, \%$ & 29 & $11.5 \%$ & 67 & 26.5 & \\
\hline High & $\mathrm{N}, \%$ & 1 & $0.4 \%$ & 1 & $0.4 \%$ & \\
\hline
\end{tabular}

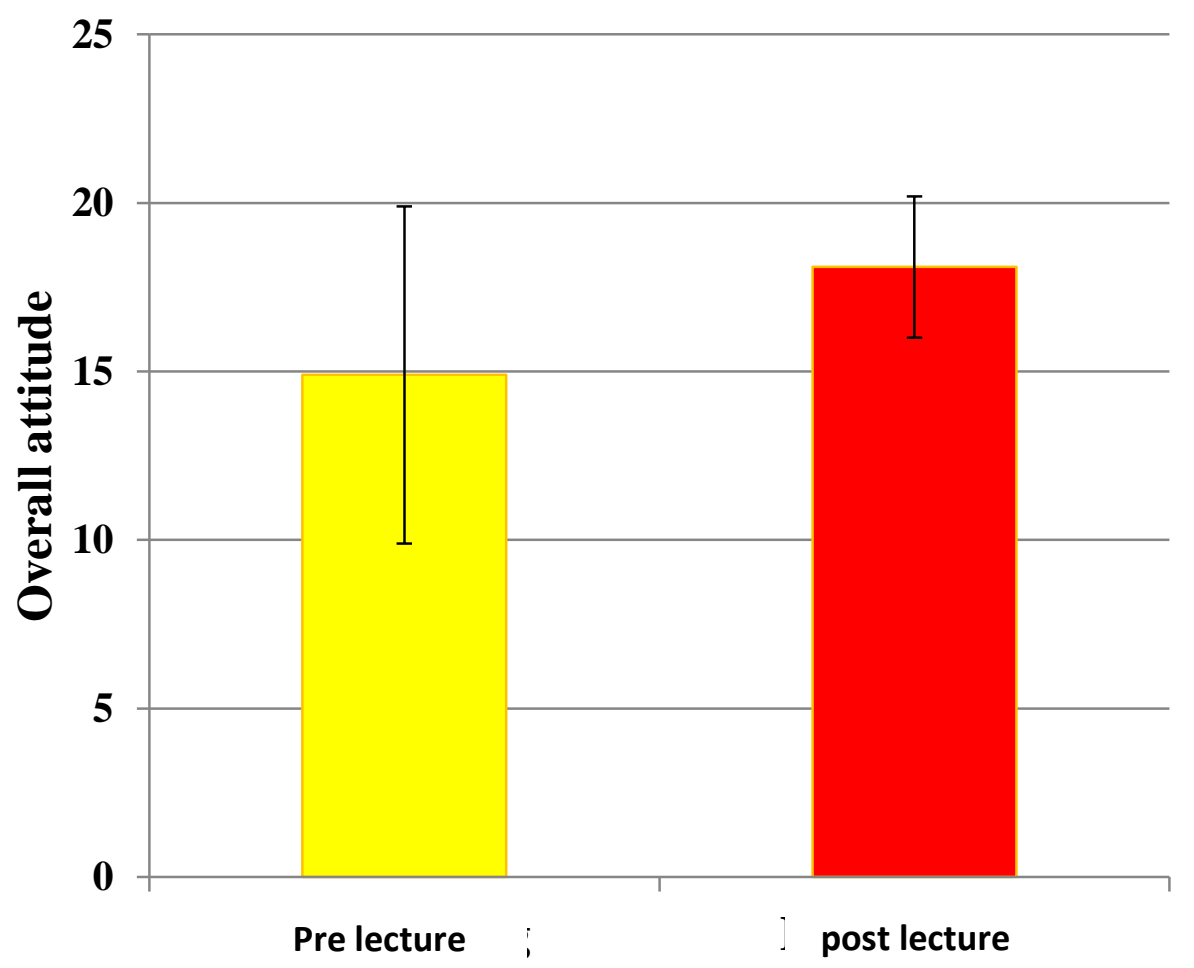

Fig (3) Overall attitude score of the teachers before and after the lecture.

Overall attitude

$\square$ I Pre lecture $\square$ post lecture

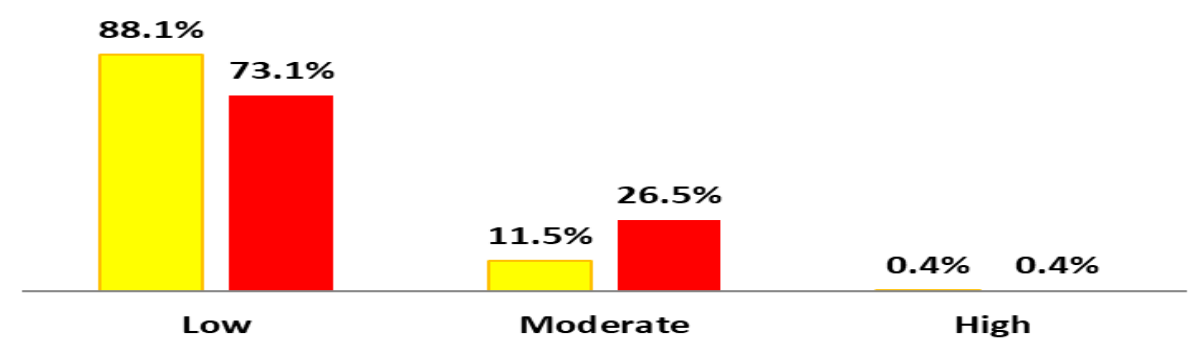

Fig (4) Overall attitude categories before and after the lecture.

When the knowledge score before and after lecture was compared according to socio-demographic characteristics of participants, knowledge score increased significantly after lecture in each class. 
Table(4) Comparison of knowledge score before and after lecture according to socio-demographic characteristics of participants.

\begin{tabular}{|c|c|c|c|c|c|c|c|c|}
\hline & & & & & Knov & score & & \\
\hline & & & & & & & & $\mathbf{P}$ \\
\hline & & & & mean & SD & mean & SD & \\
\hline 1 & Sex & Male & 38 & 18.8 & 4.7 & 25.5 & 3.5 & $<0.001$ \\
\hline & & Female & 215 & 18.7 & 5.8 & 24.7 & 2.8 & $<0.001$ \\
\hline 2 & Age & $<30$ & 50 & 18.5 & 6.4 & 25.3 & 3.5 & $<0.001$ \\
\hline & & $30-45$ & 92 & 18.0 & 5.5 & 25 & 2.3 & $<0.001$ \\
\hline & & $>45$ & 111 & 19.3 & 5.3 & 24.4 & 3.1 & $<0.001$ \\
\hline 3 & Marital status & Single & 46 & 18.0 & 6.6 & 25.3 & 3.4 & $<0.001$ \\
\hline & & Married & 172 & 18.8 & 5.3 & 24.7 & 2.8 & $<0.001$ \\
\hline & & Other & 35 & 19.2 & 5.5 & 24.8 & 2.9 & $<0.001$ \\
\hline 4 & Educational level & Intermediate & 16 & 16.0 & 6.4 & 25.0 & 2.3 & $<0.001$ \\
\hline & & Higher & 189 & 19.0 & 5.5 & 24.7 & 2.9 & $<0.001$ \\
\hline & & Postgraduate & 48 & 18.4 & 5.5 & 25.3 & 3.1 & $<0.001$ \\
\hline 5 & Type of school & Governmental & 169 & 18.8 & 5.5 & 24.7 & 2.9 & $<0.001$ \\
\hline & & Private & 62 & 17.7 & 5.5 & 24.8 & 3.3 & $<0.001$ \\
\hline & & Special abilities & 22 & 20.9 & 5.9 & 25.6 & 2.5 & $<0.001$ \\
\hline 6 & Years of experience & $<5$ & 47 & 18.5 & 5.3 & 25.0 & 3.5 & $<0.001$ \\
\hline & & $5-10$ & 58 & 18.2 & 5.8 & 25.2 & 2.5 & $<0.001$ \\
\hline & & $>10$ & 148 & 19.0 & 5.6 & 24.6 & 2.9 & $<0.001$ \\
\hline 7 & Specialty & Literary & 109 & 18.6 & 5.1 & 24.3 & 2.7 & $<0.001$ \\
\hline & & Scientific & 86 & 19.0 & 5.7 & 24.6 & 2.8 & $<0.001$ \\
\hline & & Activities & 58 & 18.3 & 6.3 & 26.1 & 3.2 & $<0.001$ \\
\hline
\end{tabular}

When the attitude score before lecture was compared with after lecture according to socio-demographic characteristics of participants, it was showed that attitude score increased significantly after lecture in each class.

Table (5) Comparison of attitude score before and after lecture according to socio-demographic characteristics of participants.

\begin{tabular}{|c|c|c|c|c|c|c|c|c|}
\hline & & & & \multicolumn{4}{|c|}{ Attitude score } & \multirow{3}{*}{$\mathbf{p}$} \\
\hline & & & & \multicolumn{2}{|c|}{ Pre } & \multicolumn{2}{|c|}{ Post } & \\
\hline & & & & Mean & SD & mean & SD & \\
\hline \multirow[t]{2}{*}{1} & Sex & Male & 38 & 15.5 & 5.2 & 17.5 & 2.2 & $<0.001$ \\
\hline & & Female & 215 & 14.8 & 4.9 & 18.2 & 2.1 & $<0.001$ \\
\hline \multirow[t]{3}{*}{2} & Age & $<30$ & 50 & 12.9 & 5.0 & 19.4 & 1.4 & $<0.001$ \\
\hline & & $30-45$ & 92 & 15.1 & 5.2 & 17.9 & 2.3 & $<0.001$ \\
\hline & & $>45$ & 111 & 15.7 & 4.5 & 17.7 & 2.0 & $<0.001$ \\
\hline \multirow[t]{3}{*}{3} & Marital status & Single & 46 & 12.7 & 5.4 & 18.9 & 1.9 & $<0.001$ \\
\hline & & Married & 172 & 15.4 & 4.9 & 18.0 & 2.1 & $<0.001$ \\
\hline & & Other & 35 & 15.4 & 4.3 & 17.7 & 2.0 & $<0.001$ \\
\hline \multirow[t]{3}{*}{4} & Educational level & Intermediate & 16 & 13.4 & 4.8 & 18.6 & 1.1 & $<0.001$ \\
\hline & & Higher & 189 & 15.0 & 5.0 & 18.2 & 2.1 & $<0.001$ \\
\hline & & Postgraduate & 48 & 15.0 & 5.1 & 17.4 & 2.0 & $<0.001$ \\
\hline \multirow[t]{3}{*}{5} & Type of school & Governmental & 169 & 15.5 & 4.7 & 17.8 & 2.0 & $<0.001$ \\
\hline & & Private & 62 & 12.3 & 4.6 & 19.3 & 1.6 & $<0.001$ \\
\hline & & Special abilities & 22 & 17.5 & 5.4 & 16.8 & 2.2 & $<0.001$ \\
\hline \multirow[t]{3}{*}{6} & Years of experience & $<5$ & 47 & 13.4 & 4.6 & 19.3 & 1.4 & $<0.001$ \\
\hline & & $5-10$ & 58 & 14.1 & 5.3 & 18.2 & 2.2 & $<0.001$ \\
\hline & & $>10$ & 148 & 15.7 & 4.8 & 17.7 & 2.1 & $<0.001$ \\
\hline \multirow[t]{3}{*}{7} & Specialty & Literary & 109 & 14.7 & 4.6 & 18.4 & 1.8 & $<0.001$ \\
\hline & & Scientific & 86 & 15.5 & 5.3 & 17.7 & 2.3 & $<0.001$ \\
\hline & & Activities & 58 & 14.5 & 5.1 & 18.2 & 2.1 & $<0.001$ \\
\hline
\end{tabular}

According to correlational analysis, Overall attitude was significantly correlated with overall knowledge before and after lecture. 
Table (6) Correlation of overall knowledge and attitude before and after lecture.

\begin{tabular}{lccccc}
\hline & \multicolumn{5}{c}{ overall knowledge } \\
\cline { 2 - 6 } & & Before & & After & P \\
\cline { 2 - 6 } & $\mathbf{R}$ & $\mathbf{P}$ & $<0.001$ & $\mathbf{R}$ & 0.180 \\
\hline overall attitude & 0.693 & & & 0.004 \\
\hline
\end{tabular}

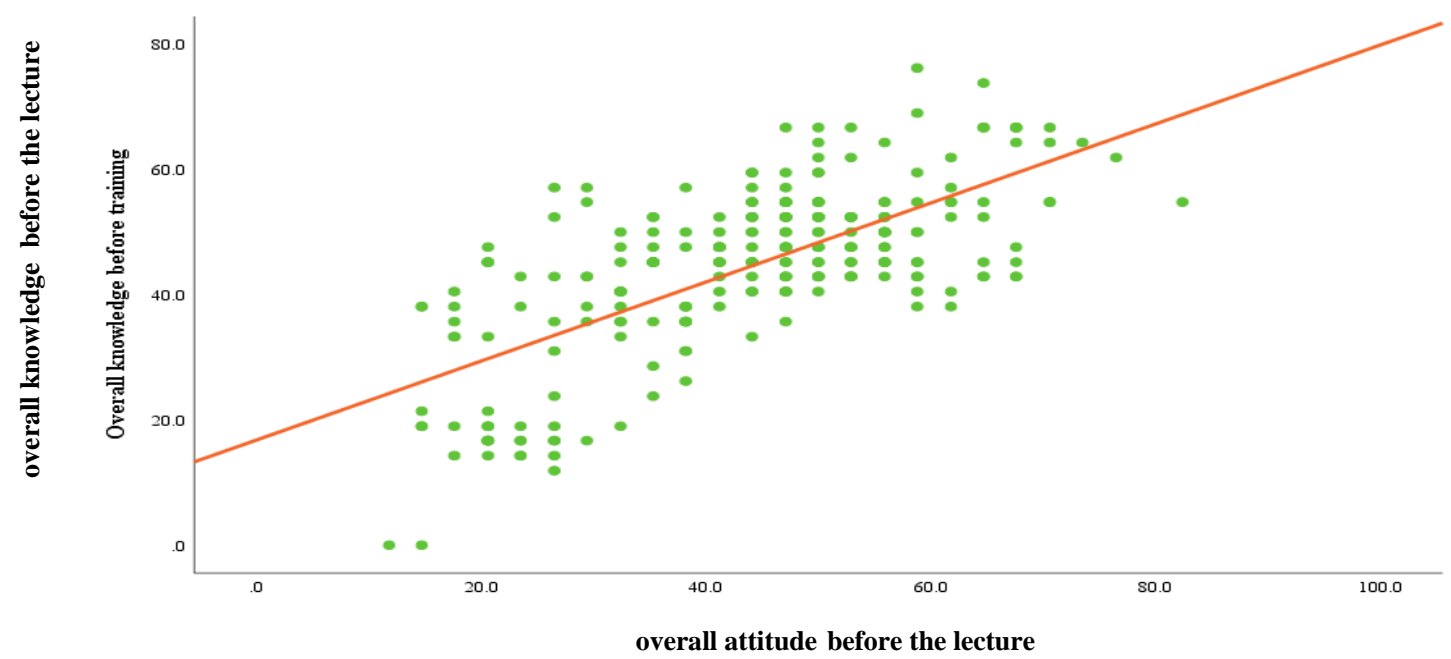

Fig (5) Correlation of overall knowledge and attitude before the lecture.

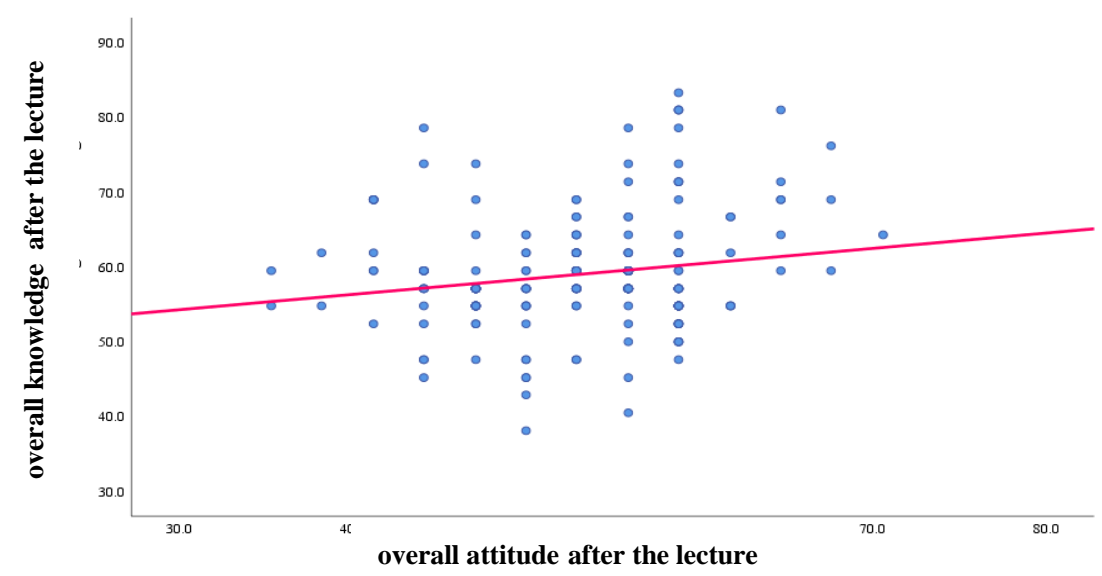

Fig (6) Correlation of overall knowledge and attitude after the lecture.

\section{Discussion}

Consideration deficiency hyperactivity issue (ADHD) is a usually analyzed neurobiological issue in youth, which influences about $5.2 \%$ of kids around the world [36]. Later audits recommend much higher commonness rate, going somewhere in the range of 5.9 and 7.2\% [43]. Youngsters burn through the majority of their daytime at schools. Hence, it is imperative to distinguish youngsters with $\mathrm{ADHD}$ and actualize unique instructive ways to deal with assistance them beat any scholarly and mental troubles [8]. Subsequently, the points of the current investigation were: a) to analyze the information and perspectives of elementary teachers about ADHD in Menya El-Qamh city, Sharika, Egypt. b) depict the connection between their insight and demeanor towards youngsters with ADHD and furthermore their training. The outcomes propose that Egyptian educators may need information about ADHD and had negative mentalities towards youngsters with ADHD.

\subsection{Teachers information on ADHD}

We report that educators' information about ADHD was low with the mean general information score being under half right. Our outcome is reliable with research directed in Caribbean Nation, South Africa and Sri Lanka and which likewise report information scores beneath half (50) In the ebb and flow study, the most elevated recurrence of right answers about information on causes and danger variables of ADHD was additionally accomplished for food added substances $(47.4 \%)$, natural and hereditary inclination in $43.5 \%$ and increment of cerebrum power $(42.7 \%)$. The majority of members concur that poor child rearing practices $(73.1 \%)$ and family brokenness $(54.2 \%)$ could cause 
ADHD, this outcome come in concurrence with (20) which indicated that parent ruining might be a reason for ADHD and [50] in which a large portion of members answers concur with that poor child rearing, natural and hereditary inclination could cause ADHD.

It was fascinating to discover that complete information on conduct and clinical introduction of ADHD was $44.1 \%$. It was best about showing an unyielding adherence to explicit schedules or ceremonies $(69.6 \%)$, trailed by that youngster with ADHD can't sit still long enough to focus (68\%), Child with ADHD consistently need a peaceful situation to think (54.9\%), Impulsivity is a manifestation of ADHD (54.5\%), ADHD Child can focus on liveliness $\backslash$ container films on TV over 5 minutes $(53.4 \%)$, ADHD is joined by epileptic seizures $(44.7 \%)$ and Children with ADHD are malevolent $(41.9 \%)$. Thus, [37] study detailed that the instructors' information about indications and introduction of ADHD were underneath half. Additionally, (4) study expressed that the normal level of information with respect to ADHD general side effects was $15.1 \%$. Youssef et al; (2015) study indicated that couple of members addressed effectively about kids with ADHD can't sit still long enough to focus (23.1\%).

In the current investigation, about $36 \%$ of respondents detailed that ADHD understudies' IQ is lower than their companions. This comes in concurrence with [37] study which detailed $41.5 \%$.

Our investigation tried the effect of educators' ADHD information on anticipation of, managing ADHD and answers were right by $(46.3 \%, 58.7 \%$ separately). $45.1 \%$ of instructors felt that the hyperactivity of ADHD youngsters is intentional and ruinous and $66.8 \%$ of educators accept that they would upset educating measure. Correspondingly, to our result,(4)found that educators' ADHD information positively affected their forecasts of what it resembles to have an understudy with ADHD in their homeroom.

Moreover, the current examination indicated helpless instructors' information on the medicines used to oversee ADHD side effects. Drug would not be especially valuable for overseeing ADHD manifestations (i.e., they revealed not known $(42.3 \%)$ and erroneous answer (25.3\%). Our outcome comes in concurrence with [33] which announced just $20 \%$ concurred that ADHD can be treated with drugs.

\subsection{Teachers disposition of ADHD}

The subsequent significant point of this examination was to test the educators' overall demeanor towards ADHD. Most members had uplifting demeanor towards conduct of ADHD (48.4\%), and if guardians of ADHD kids are to be accused (40.3\%).

It was fascinating to recognize in our test inspirational mentality from the instructors towards the executives of ADHD (44.6\%). It was towards ADHD youngsters ought not be instructed in the standard educational system (71.9\%), ADHD kids ought to be instructed by extraordinary instructive educators $(66.4 \%)$, The additional time instructors go through with
ADHD understudies is to the detriment of understudies without ADHD (63.6\%), ADHD kids need mental help $(62.5 \%)$. Also, Brook et al; (2000) and (20) considers detailed that the majority of the instructors erroneously accept that the disciplinary edge and discipline ought to be the equivalent for ADHD students just as different colleagues (without ADHD).

In our examination, most of educators had an inspirational mentality towards anticipation of kids with ADHD, shown by more than the half level of them concur with negative explanations (for example "ADHD youngsters are at a higher danger of delinquency and getting away) and $47.8 \%$ addressed not thought about kids with ADHD have a high danger for getting discouraged. This concurred with [7] which assessed just $10.2 \%$ inspirational mentality towards ADHD kids high danger of delinquency and getting away.

It was fascinating to locate that general information and all disposition levels expanded fundamentally after talk. Likewise, generally demeanor was altogether associated with by and large information when address. This shows the individuals who find out about ADHD additionally have a more open minded demeanor. Our outcome was in steady with [5] study which likewise demonstrated positive connection among information and disposition.

In the current examination, no noteworthy contrasts were found in basal information score as per sociosegment qualities of members yet information score expanded fundamentally after talk in each class. In challenge with our outcomes, [5] and [37] found that the instructors' information was comparative in all members paying little mind to their age, sexual orientation, conjugal status, long periods of experience and instructive level. This finding was contradictory with a past report which found that educator's long periods of encouraging experience was decidedly identified with ADHD information [38, 51] indicated that neither age nor sexual orientation was found to affect absolute information scores yet instructors with a graduate degree scored higher than those with no talk.

In the current examination, Lower basal demeanor score was fundamentally connected with socio-segment qualities of members like more youthful age, singles, tuition based schools, less long periods of experience. While instructive level, and strength classes didn't connect with basal demeanor score. Additionally, demeanor score expanded altogether after talk in each class as indicated by socio-segment qualities of members. Our outcomes are steady with past examinations that demonstrated instructors with more work experience would be advised to mentalities towards youngsters with ADHD $[9,4]$.

Our information propose that the purpose behind the absence of the information is because of the absence of instruction. Instructors with ace's level training scored most elevated mentality about ADHD, as they may get address explicitly concerning ADHD while educating. This last point is particularly significant as momentary intercessions (multi week) and electronic mediations 
have been appeared to quickly improve information about ADHD, with benefits going on for in any event a half year [1, 37, 16 and 42].

\section{Conclusion}

Instructors with address in ADHD are more educated and more certain about their capacities with regards to showing youngsters with ADHD.

Generally, instructors' information about ADHD was low. In this way, there is a requirement for instructors to turn out to be more taught about the condition and better furnished to manage these kids. In-administration instruction concerning ADHD has been found to fundamentally improve information, mentalities, and the executives aptitudes among instructors, a finding upheld by our information.

Given that instructors in our investigation likewise exhibited uplifting mentalities toward ADHD, we suggest that in-administration address concerning ADHD and other youth formative issues be joined inside the training framework. It is normal that such intercessions can build distinguishing proof of kids with ADHD, give instructors more noteworthy trust in their capacity to deal with these kids, and improve generally speaking study hall the executives inside the schools. Discoveries from our investigation feature that there is a requirement for proceeded with instruction of instructors with a unique accentuation on its etiology and treatment, which are the primary zones where continuing confusions appended to ADHD.

The voices of youngsters with ADHD are beginning to be heard; they have their own perspectives about their challenges and what's in store of treatment; they ought to be engaged with the educated assent measure and their viewpoints completely considered. Our far and wide message bolsters the standards of data sharing and working in association.

\section{Limitations}

Our investigation was finished by drawing instructors by and large from Menya El-Qamh city, Sharkia governorate, Egypt. There might be overrepresentation or underrepresentation of certain individuals from the example, subsequently conceivably restricting this current examination's generalizability.

The survey utilized was a self-report poll. While selfreport surveys are handily managed and moderately simple to investigate, there might be an inclination to react with regards to socially acknowledged standards. Absence of care and enthusiasm towards the investigation and the negative demeanor in doing the poll, the way that expressing one's feeling or placing it in studies isn't essential for the way of life, in this manner the instructors are not used to expressing their assessment and the failure to communicate their conclusions towards ADHD because of the dread from the position figures in the schools or instructive organization. At last, information assortment for this investigation occurred before the finish of the school term, when instructors were more bustling that typical with their obligations. Because of time limitations, they couldn't address all the inquiries so the analyst dismissed the uncompleted ones. This reality conceivably influenced the quantity of finished polls returned, and inside this unique circumstance, it is conceivable that the educators who completed the surveys may have had earlier enthusiasm for ADHD.

\section{Reference}

[1] A. P. Aguiar, R. R. Kieling, A. C. Costa, N.Chardosim , B. V. Dorneles, Increasing teachers' knowledge about ADHD and learning disorders: An investigation on the role of a psychoeducational intervention. Journal of Attention Disorders, Vol.18, PP.691-698,2014.

[2] M.Albert, P.Rui, J.J.Ashman, Physician office visits for attention-deficit/hyperactivity disorder in children and adolescents aged 4-17 years: United States, PP.2012-2013,2017.

[3] J.M. Alkhateeb, M.S. Alhadidi, ADHD Research in Arab countries: A systematic review of literature. Journal of Attention disorders, Vol.23(13),2019.

[4] EY.Al-Moghamsi , A .Aljohani , Elementary School Teachers' Knowledge of Attention Deficit/Hyperactivity Disorder. J Family Med Prim Care, $\quad$ Vol.7(5), PP.907-915. Doi,10.4103/jfmpc.jfmpc_183_18,2018.

[5] H. Al-Omari, MA. Al-Motlaq , H.Al-Modallal , Knowledge of and Attitude towards Attentiondeficit Hyperactivity Disorder among Primary School Teachers in Jordan. Child Care in Practice, Vol. 21, No. 2, pp. 128-139,2015.

[6] American Psychiatric Association and American Psychiatric Association, Diagnostic and statistical manual of mental disorders, PP. DSM-5,2013.

[7] D.Anderson, S.Watt , W. Noble, Knowledge of attention deficit hyperactivity disorder (ADHD) and attitudes toward teaching children with ADHD: The role of teaching experience. Psychology in the Schools, Vol.49, 511-525. Doi, PP.10.1002/pits.21617,2012.

[8] B.Barnett, P.Corkum, N.Elik, A web-based intervention for elementary school teachers of students with attention-deficit/hyperactivity disorder (ADHD). Psychological Services, Vol.9, PP.227-230,2012.

[9] A.Z. Bauer, Developmental effects of analgesics: State of the epidemiologic evidence (Doctoral dissertation, University of Massachusetts Lowell), 2015.

[10] B. Bekle, Knowledge and attitudes about attentiondeficit hyperactivity disorder (ADHD): A comparison between practicing teachers and undergraduate education students. Journal of Attention Disorders, Vol.7, PP. 151-161,2004.

[11] J.Biederman, M.DiSalvo, R.Fried, K.Y. Woodworth, Quantifying the Protective Effects of Stimulants on Functional Outcomes in AttentionDeficit/Hyperactivity Disorder: A Focus on 
Number Needed to Treat Statistic and Sex Effects. Journal of Adolescent Health, Vol.65(6), 2019.

[12] U. Brook, N. Watemberg, D.Geva, Attitude and knowledge of attention deficit hyperactivity disorder and learning disability among high school teachers. Patient Educ Couns, Vol.40, PP.247-52, 2000.

[13] D. F.Curtis, S.Pisecco, R. J. Hamilton, Teacher perceptions of classroom interventions for children with ADHD: A cross-cultural comparison of teachers in the United States and New Zealand. School Psychology Quarterly, Vol.21, PP. 171196,2006.

[14] M.L. Danielson, S.N. Visser, A.Chronis-Tuscano, G.J.DuPaul, A national description of treatment among United States children and adolescents with attention-deficit/hyperactivity disorder. The Journal of pediatrics, Vol.192,2018.

[15] M.S. DeWitt, Attention Deficit Hyperactivity Disorder (ADHD): Executive Functioning Skills as a Therapeutic Tool for Children and Adolescents (Doctoral dissertation, California Southern University), 2019.

[16] D.DiBattista, M.Shepherd, Primary school teachers' beliefs and advice to parents concerning sugar consumption and activity in children. Psychological Reports, Vol.72, PP.47-55,1993.

[17] G.F. Gaastra, Y.Groen, L. Tucha, O.Tucha, The effects of classroom interventions on off-task and disruptive classroom behavior in children with symptoms of attention-deficit/hyperactivity disorder: A meta-analytic review. PloS one, Vol.11(2),2016.

[18] A .Ghanizadeh, MJ. Bahredar ,SR. Moeini ,Knowledge and attitudes towards attention deficit hyperactivity disorder among elementary school teachers. Patient Education and Counseling, Vol.63 , PP. 84-88,2006.

[19] P.Giannopoulou, E.Korkoliakou, A.Pasalari, Douzenis , Greek teachers' knowledge about attention deficit hyperactivity disorder. Psychiatriki, Vol.28, PP.226-233,2017.

[20] P.A. Graziano, A.Garcia, Attention-deficit hyperactivity disorder and children's emotion dysregulation: A meta-analysis. Clinical psychology review, Vol.46,2016.

[21] C.M. Hartung, E.K. Lefler, W.H.Canu, A.E.Stevens, DSM-5 and other symptom thresholds for ADHD: Which is the best predictor of impairment in college students? Journal of attention disorders, Vol.23(13,2019.

[22] A.Mohammad Al-Motlaq, Hanan Al-Modallal (): Knowledge of and Attitude towards Attentiondeficit Hyperactivity Disorder among Primary School Teachers in Jordan. Child Care in Practice,Vol. 21, No. 2, pp. 128-139, 2015.

[23] L.Jerome, M.Gordon, P.Hustler, A comparison of American and Canadian teachers' knowledge and attitudes toward attention deficit hyperactivity disorder (ADHD). Canadian Journal of Psychiatry, Vol.39, PP.563-567,1994.

[24] H. A. Jones, A.Chronis-Tuscano, Efficacy of teacher in-service training for attentiondeficit/hyperactivity disorder. Psychology in Schools, Vol.45, PP.918-929. ,2008.

[25] J. M.Kos, A. L. Richdale, M. S. Jackson, Knowledge about attention-deficit/hyperactivity disorder: A comparison of in-service and preservice teachers. Psychology in the Schools, Vol.41, PP. 517- 526,2004.

[26] A.P. Latouche, M.Gascoigne, In-service training for increasing teachers' ADHD knowledge and selfefficacy. Journal of attention disorders, Vol.23(3),2019.

[27] A .Lopez-Lopez, A. Lopez-Lafuente, J. Eiris-Punal, A Study of Primary School Teachers' Knowledge of Attention Deficit Hyperactivity Disorder, Vol.1;66(01), PP.121-126,2018.

[28] C.Mohr-Jensen, T.Steen-Jensen, M.Bang-Schnack, What do primary and secondary school teachers know about ADHD in children? Findings from a systematic review and a representative, nationwide sample of Danish teachers. Journal of attention disorders, Vol.23(3),2019.

[29] M .Moldavsky, K .Sayal , Knowledge and Attitudes about Attention-Deficit/ Hyperactivity Disorder (ADHD) and its Treatment: The Views of Children, Adolescents, Parents, Teachers and Healthcare Professionals. Curr Psychiatry Rep , Vol.15, PP.377 DOI 10.1007/s11920-013-0377-0., 2013.

[30] JL .Ohan, N. Cormier, SL. Hepp, Does knowledge about attention deficit/hyperactivity disorder impact teachers' reported behaviors and perceptions? Sch Psychol Q, Vol.23, PP.436-449, doi: 10.1037/1045-3830.23.3.436. ,2008.

[31] J.L. Park, K.L. Hudec, C.Johnston, Parental ADHD symptoms and parenting behaviors: A metaanalytic review. Clinical psychology review, Vol.56 ,2017.

[32] G. Polanczyk, M.S .de Lima, B.L. Horta, J. Biederman,. The worldwide prevalence of ADHD: A systematic review and metaregression analysis. Am J Psychiatry, Vol.164, PP.942-948, doi: 10.1176/ajp.2007.164.6.942,2007.

[33] M. D. A. Rodrigo, D.Perera, V. P.Eranga, S. S. Williams, The knowledge and attitude of primary school teachers in Sri Lanka towards childhood attention deficit hyperactivity disorder. Ceylon Medical Journal, Vol.56, PP.51-54,2011.

[34] M. J. Sciutto, C. J. Nolfi, C.Bluhm, Effects of child gender and symptom type on referrals for ADHD by elementary school teachers. Journal of Emotional and Behavioral Disorders, Vol.12, PP. 247-253,2004.

[35] P.Sharma, R.K. Gupta, R. Banal, M.Majeed, Prevalence and correlates of Attention Deficit Hyperactive Disorder (ADHD) risk factors among school children in a rural area of North India. 
Journal of Family Medicine and Primary Care, Vol.9(1),2020.

[36] N.S.Shehab, Lebanese counselors' perceptions of ADHD, the methods of intervention used, and the DSM-5 as a culturally appropriate assessment tool (Doctoral dissertation), 2017.

[37] J.Stroh, W.Frankenberger, L.Cornell-Swanson, C.Wood, The use of stimulant medication and behavioral interventions for the treatment of attention deficit hyperactivity disorder: A survey of parents' knowledge, attitudes, and experiences. Journal of Child and Family Studies, Vol.17, PP. 385-401. doi:10.1007/s10826-007-9149-y,2008.

[38] E. U.Syed, S. A. Hussein, Increase in teachers' knowledge about ADHD after a week-long training program: A pilot study. Journal of Attention Disorders, Vol.13, PP. 420-423,2010.

[39] R. Thomas, J. Doust, S. Sanders, P.Glasziou, Worldwide prevalence of attention-deficit hyperactivity disorder: a systematic review. Paper presented at preventing overdiagnosis conference, 10-12 September, Darmouth USA,2013.

[40] M.Thompson, L. Wilkinson, H.Woo, Social Characteristics as Predictors of ADHD Labeling across the Life Course. Society and Mental Health, 2020.

[41] R.L.Vereb, J.C. DiPerna, Researchbrief: Teachers' knowledge of ADHD, treatment for ADHD, and treatment acceptability: An initial investigation. School Psychology Review, Vol.33, PP.421428,2004.

[42] T.W. Wadian, T.L.Sonnentag, T.L. Jones, M.A.Barnett, Role of Fault Attributions and Other Factors in Adults' Attitudes Toward Hypothetical Children With an Undesirable Characteristic. Psychological reports, Vol.122(1),2019.

[43] L.J. Wang, K.C.Yang, S.Y.Lee, C.J.Yang, Initiation and persistence of pharmacotherapy for youths with attention deficit hyperactivity disorder in Taiwan. PLoS One, Vol.11(8), 2016.

[44] J.West, M.Taylor, S.Houghton, A comparison of teachers' and parents' knowledge and beliefs about attention-deficit/ hyperactivity disorder (ADHD). School Psychology International, Vol.26, PP. 192208,2005.

[45] M.L.Wolraich, J.F.Hagan, C. Allan, E.Chan, Clinical practice guideline for the diagnosis, evaluation, and treatment of attentiondeficit/hyperactivity disorder in children and adolescents. Pediatrics, Vol.144(4), 2019.

[46] M.K Youssef, Gerard Hutchinson1, F.Farid , Knowledge of and Attitudes Toward ADHD Among Teachers: Insights from a Caribbean Nation. SAGE Open, PP. 1 -8,2015. 